\title{
Effects of preheating temperatures on the formation of sandwich compression and density distribution in the compressed wood
}

\author{
Ren $\mathrm{Li}^{1,2} \cdot$ Zhiqiang Gao $^{1,2} \cdot$ Shanghuan Feng ${ }^{3} \cdot$ Jianmin Chang ${ }^{2} \cdot$ Yanmei Wu$^{1} \cdot$ Rongfeng Huang $^{1}$
}

Received: 26 March 2018 / Accepted: 18 August 2018 / Published online: 31 August 2018

(C) The Japan Wood Research Society 2018

\begin{abstract}
Sandwich compression of wood that can control the density and position of compressed layer(s) in the compressed wood provides a promising pathway for full valorization of low-density plantation wood. This study aims at investigating the effects of preheating temperatures $\left(60-210^{\circ} \mathrm{C}\right)$ on sandwich compression of wood, with respect to density distribution, position and thickness of the compressed layer(s). Poplar (Populus tomentosa) lumbers with moisture content below $10.0 \%$ were first soaked in water for $2 \mathrm{~h}$ and stored in a sealed plastic bag for $18 \mathrm{~h}$, the surface-wetted lumbers were preheated on hot plates at $60-210{ }^{\circ} \mathrm{C}$ and further compressed from 25 to $20 \mathrm{~cm}$ under $6.0 \mathrm{MPa}$ at the same temperature on the radial direction. The compressed lumbers were characterized in terms of density distribution, position and thickness of compressed layer(s). It was found that depending on preheating temperatures, sandwich compressed wood with three structural modes, namely, surface compressed wood, internal compressed wood and central compressed wood can be formed. Density of the compressed layer(s) in wood increased gradually as a result of the elevated preheating temperatures. Higher preheating temperatures gave rise to bigger distance between compressed layer(s) and the surface, and preheating temperature elevation from 90 to $120^{\circ} \mathrm{C}$ contributed to a maximal distance increase of $2.71 \mathrm{~mm}$. In addition, higher preheating temperatures resulted in bigger thickness of compressed layer(s) over $60-150{ }^{\circ} \mathrm{C}$ and temperature elevation from 120 to $150{ }^{\circ} \mathrm{C}$ lead to the layers integration from two into one. Further temperature elevation over $150{ }^{\circ} \mathrm{C}$ reduced the thickness of the compressed layer in wood. SEM scanning suggested that cell wall bucking rather than cell wall crack occurred in compressed layer(s) and transition layer(s).
\end{abstract}

Keywords Sandwich compression · Preheating temperature $\cdot$ Position of the compressed layer(s) $\cdot$ Thickness of the compressed layer(s) $\cdot$ Density distribution

\section{Introduction}

Traditional wood compression involving whole wood compression has been widely used to modify solid wood for improved physical and mechanical properties. In traditional wood compression, high compression ratio is required for

Ren Li and Zhiqiang Gao contributed equally to this work.

Rongfeng Huang

huangrf@caf.ac.cn

1 Research Institute of Wood Industry, Chinese Academy of Forestry, Beijing 100091, People's Republic of China

2 College of Materials Science and Technology, Beijing Forestry University, Beijing 100083, People's Republic of China

3 Department of Energy Technology, Aalborg University, Pontoppidanstræde 111, 9220 Aalborg Øst, Denmark the satisfactory properties of compressed wood in terms of surface density and hardness [1]. While wood surface compression is an essential pathway for enhancing the density and hardness of wood surfaces [2-6]. It has been reported that polar wood preheated at $180{ }^{\circ} \mathrm{C}$ for $350 \mathrm{~s}$ can be softened and thus compressed into the required compressed wood with a relatively high surface density [2], but cell walls inside the compressed wood are also compressed as well. Air dried wood with surface sprayed with water can be compressed at $160{ }^{\circ} \mathrm{C}$ or $180^{\circ} \mathrm{C}$ and compression for 0.4 min can yield surface compressed wood with peak densities of $650-800 \mathrm{~kg} / \mathrm{m}^{3}$ [3]. However, the thickness of the compressed layers is very small and the density distribution is not controllable.

In our previous research [4], we developed a technology for sandwich compression of solid wood, which can control both the thickness of compressed layer(s) and density distribution. The most important advantage of this 
technology is that the compressed layer(s) position is controllable. Furthermore, this technology can be scaled up very easily. In this technology, solid wood was first soaked in water to wet the surface, then wood was preheated and hot compressed $180^{\circ} \mathrm{C}$ in the radial direction. Compressed woods with compressed layer(s) either on the wood surfaces or inside wood were obtained, and the position of compressed layer(s) can be controlled at wood surfaces, 1 or $3 \mathrm{~mm}$ below wood surface, or at the center of wood by adjusting the preheating time (10, 40, 240 and $420 \mathrm{~s})$. Sandwich compression is achieved by moving water from wood surface(s) to wood interior, and transferring heat from wood surface(s) to wood core. Water and temperature are the determining factors for solid wood softening $[5,6]$. Temperature is an extremely important parameter affecting the moisture diffusion in wood $[7,8]$. When the temperature is $90{ }^{\circ} \mathrm{C}$, the radial moisture diffusion coefficient in wood is over twice of that at $60{ }^{\circ} \mathrm{C}$ [9]. When the temperature is above $100^{\circ} \mathrm{C}$, water in wood transforms into vapor. For wood with a moisture content of $24 \%$, heating at 120,160 and $200{ }^{\circ} \mathrm{C}$ contributes to steam pressures of $0.20,0.45$ and $0.60 \mathrm{MPa}$ inside wood, respectively [10], which accelerates moisture migration in wood [11, 12]. In addition, temperature also affects the heat conductivity of wood.

Based on our previous studies on the formation of wood sandwich compression [4] and fixation of sandwich-compressed wood under atmospheric pressure and pressurized steam condition [13], this study further investigated the effects of preheating temperatures on the compression layer(s) formation and density distribution in sandwichcompressed wood. Moreover, the density and thickness of compressed layer(s) and the distance between compressed layer(s) and wood surface were analyzed, to explore the thermal heating conditions for better controlling the position, thickness as well as density of the compressed layer(s).

\section{Materials and methods}

\section{Materials}

Twenty-five-year-old white poplar (Populus tomentosa) trees, with diameters of $25-35 \mathrm{~cm}$ at breast height were harvested from a plantation forest in Guan county, Shandong province, China. Clear lumbers with the size of $500 \mathrm{~mm}$ $(L) \times 150 \mathrm{~mm}(T) \times 50 \mathrm{~mm}(R)$ were cut from 5 poplar logs. The lumbers were then kiln-dried to moisture content (MC) levels under $10.0 \%$ and further processed into the dimension of $400 \mathrm{~mm}(L) \times 120 \mathrm{~mm}(T) \times 25 \mathrm{~mm}(R)$ for sandwich compression.

\section{Methods}

\section{Wood compression process}

The detailed poplar wood compression process follows the procedures applied in our previous study [13]. Before compression, poplar wood specimens were first coated with paraffin on the transverse sections, then soaked in water for $2 \mathrm{~h}$ and stored in sealed plastic bags for $18 \mathrm{~h}$ $(\mathrm{MC}=18.3 \%)$. The specimens were then preheated at $60,90,120,150,180$ or $210{ }^{\circ} \mathrm{C}$, respectively for $12 \mathrm{~min}$. After the preheating process, intermittent compression was applied on the preheated wood with a pressure of $6.0 \mathrm{MPa}$. Each intermittent compression cycle consists of $3 \mathrm{~s} \mathrm{com-}$ pression time and $10 \mathrm{~s}$ unloading time. The specimens were compressed from the original thickness of 25 to $20 \mathrm{~mm}$ after 5 compressing cycles. The final compression thickness of $20 \mathrm{~mm}$ was maintained at the compressing temperatures for $30 \mathrm{~min}$, then the compression was hold till the complete cooling down of the wood specimen. Five replicates were performed at each preheating and compressing temperature.

\section{Characterizations of sandwich compressed wood}

Density distribution Specimens with a dimension of $50 \mathrm{~mm}$ $(L) \times 50 \mathrm{~mm}(T) \times 20 \mathrm{~mm}(R)$ were cut from the middle of the width of the sandwich-compressed wood for density distribution tests. The density distribution was measured using a cross-sectional X-ray densitometer (D-31785 Hameln) with a step of $20 \mu \mathrm{m}$ scanning from the top surface to the bottom surface. Before density distribution tests, all the specimens were conditioned in $65 \%$ relative humidity at $20{ }^{\circ} \mathrm{C}$ to constant weights.

Determination of compressed layer(s) The mean density and maximal density of poplar wood control specimen is 0.44 and $0.49 \mathrm{~g} / \mathrm{cm}^{3}$, respectively. Compressed layer(s) was determined as described in our previous study [13]. For sandwich-compressed wood, the compressed layer is identified as the part with density of $20 \%$ higher than the maximal density of the control specimen; the region whose density is less than the maximal density of the control is considered as the uncompressed layer; regions between the compressed layer and uncompressed layer is defined as the transition layer. In this paper, the densities of compressed layer, uncompressed layer and transition layer were in the ranges of $>0.59 \mathrm{~g} / \mathrm{cm}^{3},<0.49 \mathrm{~g} / \mathrm{cm}^{3}, 0.49-0.59 \mathrm{~g} / \mathrm{cm}^{3}$, respectively. Position of compressed layer(s) is defined as the distance from the edge of compressed layer(s) to the associated surface(s) of the compressed wood. 
Morphological structure All the compressed woods and control specimen were scanned by scanning electric microscope (SEM) to investigate the morphological structure change. Specimens consisting of compressed layer, transition layer and uncompressed layer were cut from the transverse section. The cutting surfaces were sputter-coated gold and scanned in an S4800 SEM with the magnifications of $40 \times$ and $200 \times$, to observe the cell wall deformation.

\section{Results and discussion}

\section{Formation of compressed layers in sandwich-compressed wood}

Figure 1 shows the photographs (left) and the associated soft $\mathrm{X}$-ray images (right) of transverse section in sandwich-compressed wood. The compressed layer(s) is shown as the dark layer(s) in the photographs of transverse section, while in the soft X-ray images, the compressed layer(s) is the high luminance layer(s). As shown in Fig. 1, the sandwich-compressed wood with typical compressed layer(s) is observed after soaking in water and preheating/compressed at $60-210{ }^{\circ} \mathrm{C}$. Moreover, the distance between the compressed layer(s) and the corresponding wood surface increases gradually with the elevated preheating temperatures. When preheating temperature is below $120{ }^{\circ} \mathrm{C}$, two compressed layers can be observed. At $60{ }^{\circ} \mathrm{C}$, the compressed layers are formed on the surface while at 90 and $120^{\circ} \mathrm{C}$, two compressed layers exist inside wood. Further preheating temperature elevation
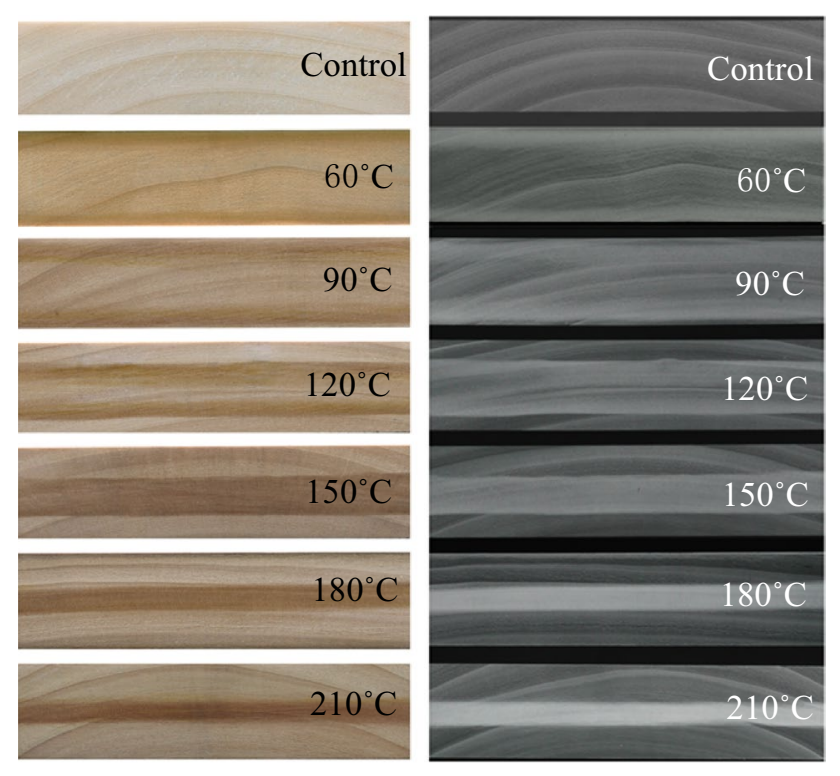

Fig. 1 Photograph images (left) and soft X-ray images (right) of transverse section of sandwich compressed wood preheated at different temperatures to $150{ }^{\circ} \mathrm{C}$ integrates the two compressed layers into one. When the preheating temperature further elevates to 180 or $210{ }^{\circ} \mathrm{C}$, the only one compressed layer narrows down, with an increased density as evidenced by the soft X-ray images.

SEM was employed to investigate the morphologic structure of the transverse section in the compressed wood. As illustrated in Fig. 2, both compressed layer and uncompressed layer can be observed in a thickness range of $5 \mathrm{~mm}$ in the transverse section. Cell lumens in compressed layer almost disappear and the cell walls completely deform, while in the uncompressed layer, wood cell wall and lumen are both intact. In the compressed layer region, most of the vessels and cell lumen of wood fiber disappear, and only a few lumens of the deformed cell are incompletely closed in the low-magnification image, while some cell lumens of wood fiber are still observable even in the high-magnification image. In the transition region, vessels and wood fibers deform to some extent, but the cell lumens are still clearly visible. As for the uncompressed layer, there are no cell deformations on the vessels or wood fiber cells. Even though buckling deformation occurs on the wood cells of the compressed layer and the transition layer, no cracks of the cell walls are found, which could be attributed to the fullysoftening of wood during the 12 min preheating process at $150{ }^{\circ} \mathrm{C}$.

Based on the above discussion and the positions of compressed layer(s) in compressed wood, three types of sandwich-compressed wood are proposed as Fig. 3 shows, which are respectively surface compressed wood, internal compressed wood (the compressed layer(s) located between the surface and the wood center line) and central compressed wood.

\section{Density distribution in sandwich compressed wood}

Density distribution in sandwich-compressed wood as determined by X-ray profile densitometer is shown in Fig. 4. When the preheating temperature is $60^{\circ} \mathrm{C}$, both top and bottom surfaces are compressed. As the preheating temperature elevates, the compressed layers gradually move towards the center and the two separate compressed layers integrate into one central compressed layer with two density peaks at $150{ }^{\circ} \mathrm{C}$. When the temperature further elevates from 150 to $180{ }^{\circ} \mathrm{C}$, two density peaks integrate into one, yielding one central compressed layer with characteristic high core density but low surface density. It is interesting that in our previous study [4], we found that when the compressing time extended from 10 to $420 \mathrm{~s}$, a similar change in density distribution of compressed wood that was preheated and compressed at $180{ }^{\circ} \mathrm{C}$ took place, demonstrating that the compressing time and the preheating temperature exert similar effects on the formation of sandwich-compressed layer in compressed wood. 
Fig. 2 Soft X-ray image and SEM micrographs of transverse section of sandwich compressed wood at $150{ }^{\circ} \mathrm{C}$. a image of soft $\mathrm{X}$-ray; $\mathbf{b}$ the whole micrograph of SEM; $\mathbf{c}$ Magnifications of compressed layer; $\mathbf{d}$ transition layer; e uncompressed layer
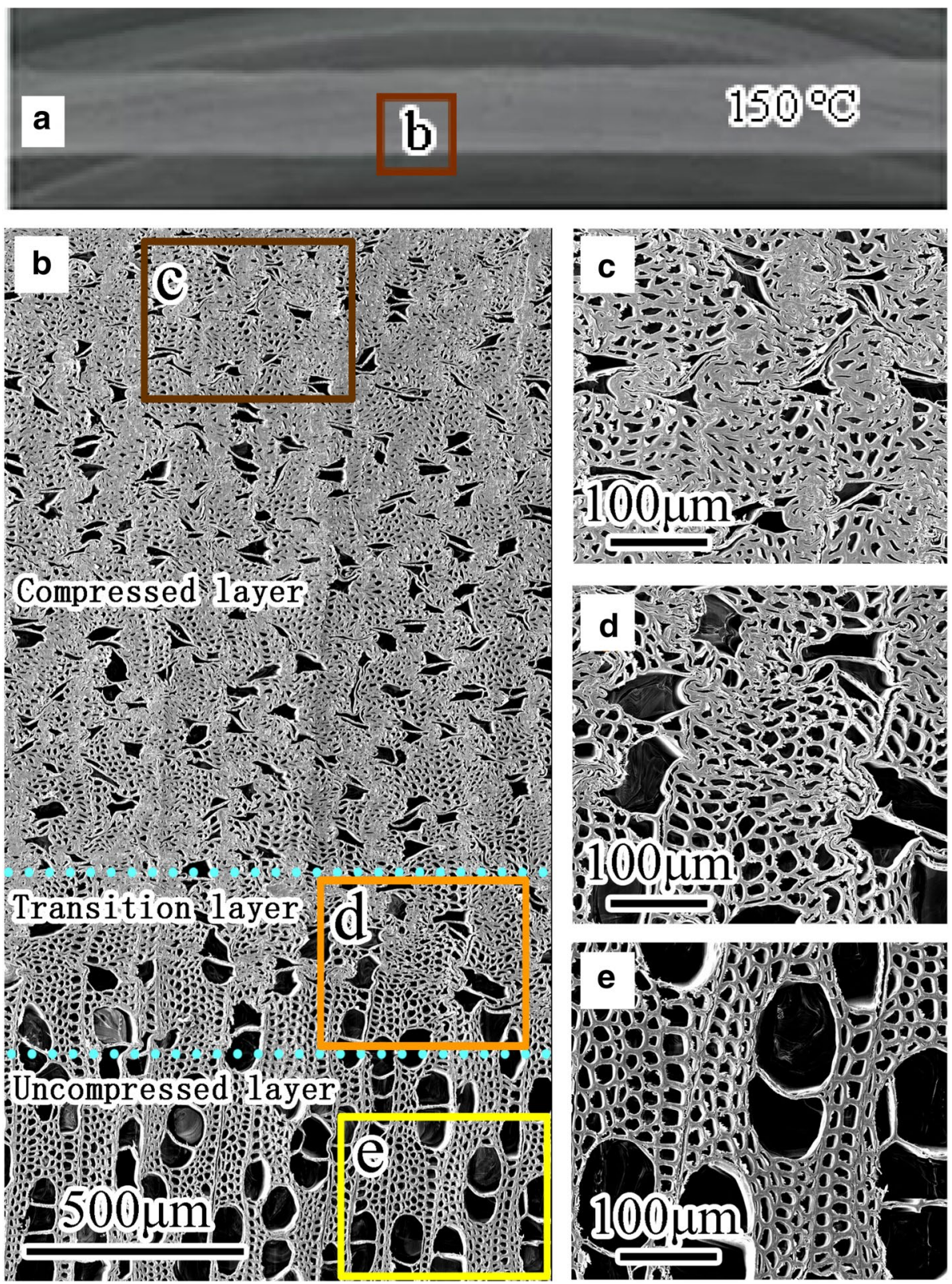

Table 1 displays the thickness, mean density and maximal density of the compressed layer(s) in sandwich-compressed wood. As for the total thickness of the compressed layer(s), it increases first, then decreases as a result of preheating temperature elevation (Table 1). When the preheating temperature is $60{ }^{\circ} \mathrm{C}$, the thickness of the compressed layer is $6.90 \mathrm{~mm}$. When the temperature is $150{ }^{\circ} \mathrm{C}$, the top and bottom compressed layers transform into one, with a maximal thickness of $8.10 \mathrm{~mm}$. Further temperature elevation decreases the thickness of the compressed layer. The mean density and maximal density of the compressed layers in the wood compressed at higher temperature are both higher than that of the compressed layers in the wood compressed at lower temperatures, but both higher than $0.61 \mathrm{~g} / \mathrm{cm}^{3}$. When the preheating temperature is $210{ }^{\circ} \mathrm{C}$, the average density and the maximal density of the compressed layer reach to the highest values of 0.71 and $0.75 \mathrm{~g} / \mathrm{cm}^{3}$, respectively, which are 61.3 and $70.5 \%$ higher than that of the control. F test shows that, at 5\% significant level, preheating temperature exerts significant effects on the mean density $(p=0.006)$ and maximal density $(p=0.002)$ of the compressed layers.

\section{Position and thickness of the compressed layer}

Figure 5 illustrates the effects of preheating temperatures on the position and maximal density of the compressed layer(s) in sandwich-compressed wood. The distance between the compressed layer(s) and wood surface gradually increases 
Fig. 3 Formation schematic diagram of the sandwich compressed wood. a populus tomentosa $\log$; b flat-sawn lumber; c three structural models of the sandwich compressed wood
C Sandwich compressed wood
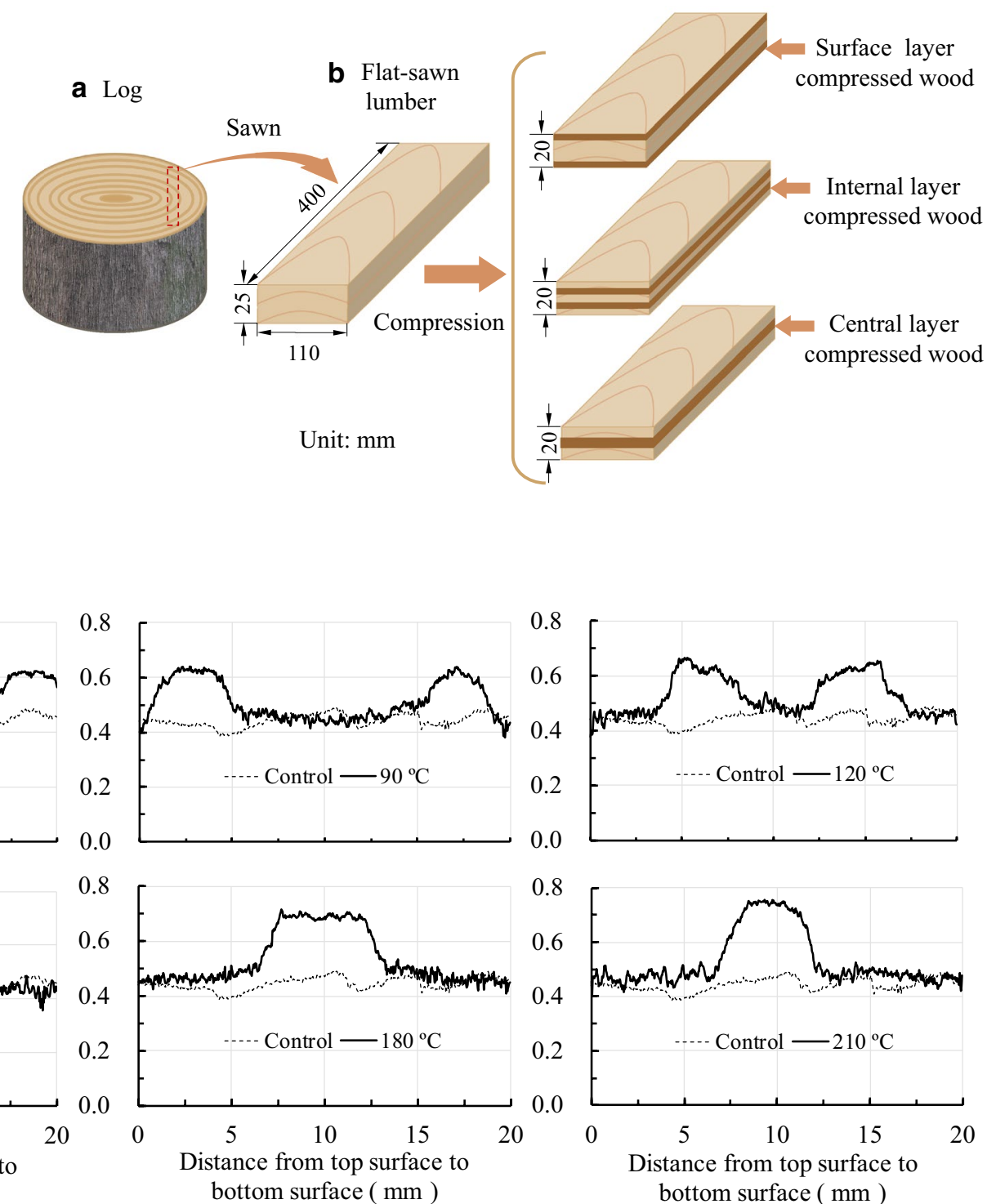

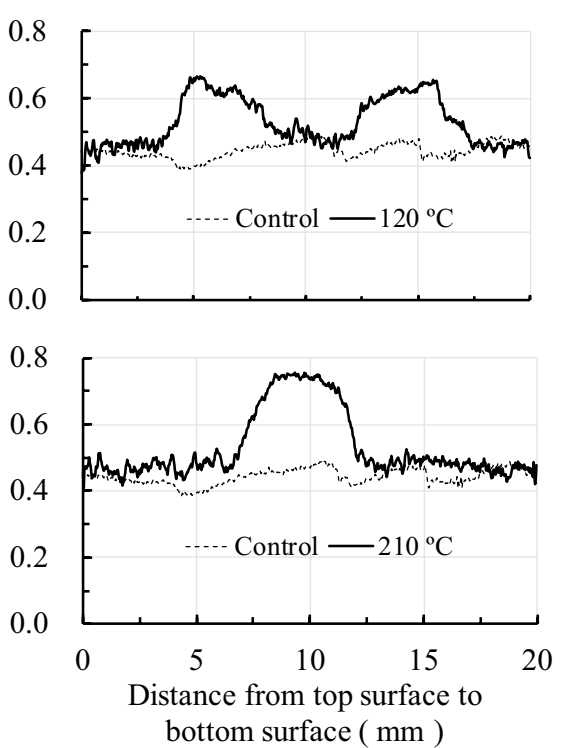

Fig. 4 Effects of preheating temperatures on the density distribution of the sandwich compressed wood

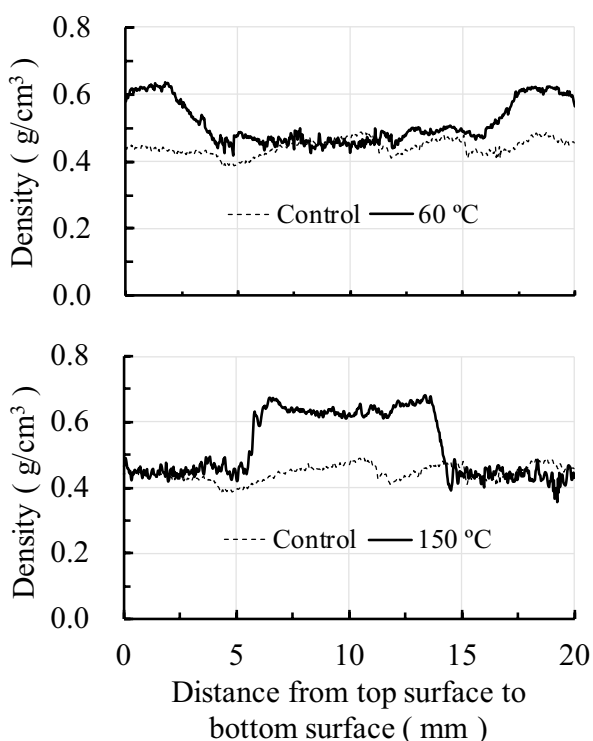

Table 1 Thickness, mean density and maximal density of the compressed layer(s) in sandwich-compressed wood

\begin{tabular}{|c|c|c|c|c|}
\hline \multirow{2}{*}{$\begin{array}{l}\text { Preheating tempera- } \\
\text { ture }\left({ }^{\circ} \mathrm{C}\right)\end{array}$} & \multicolumn{4}{|c|}{ The characteristic parameters of compressed layer(s) } \\
\hline & Number & Thickness (mm) & Mean density $\left(\mathrm{g} / \mathrm{cm}^{3}\right)$ & $\begin{array}{l}\text { Maximum } \\
\text { density }(\mathrm{g} / \\
\left.\mathrm{cm}^{3}\right)\end{array}$ \\
\hline 60 & 2 & $4.92(0.22)$ & $0.61(0.01)$ & $0.63(0.01)$ \\
\hline 90 & 2 & $5.13(0.31)$ & $0.61(0.02)$ & $0.66(0.03)$ \\
\hline 120 & 2 & $5.64(0.65)$ & $0.63(0.01)$ & $0.66(0.01)$ \\
\hline 150 & 1 & $8.10(0.05)$ & $0.64(0.01)$ & $0.68(0.01)$ \\
\hline 180 & 1 & $5.49(0.49)$ & $0.68(0.01)$ & $0.71(0.01)$ \\
\hline 210 & 1 & $4.59(0.33)$ & $0.71(0.01)$ & $0.75(0.01)$ \\
\hline
\end{tabular}

Values in () are the standard deviation of 5 runs 

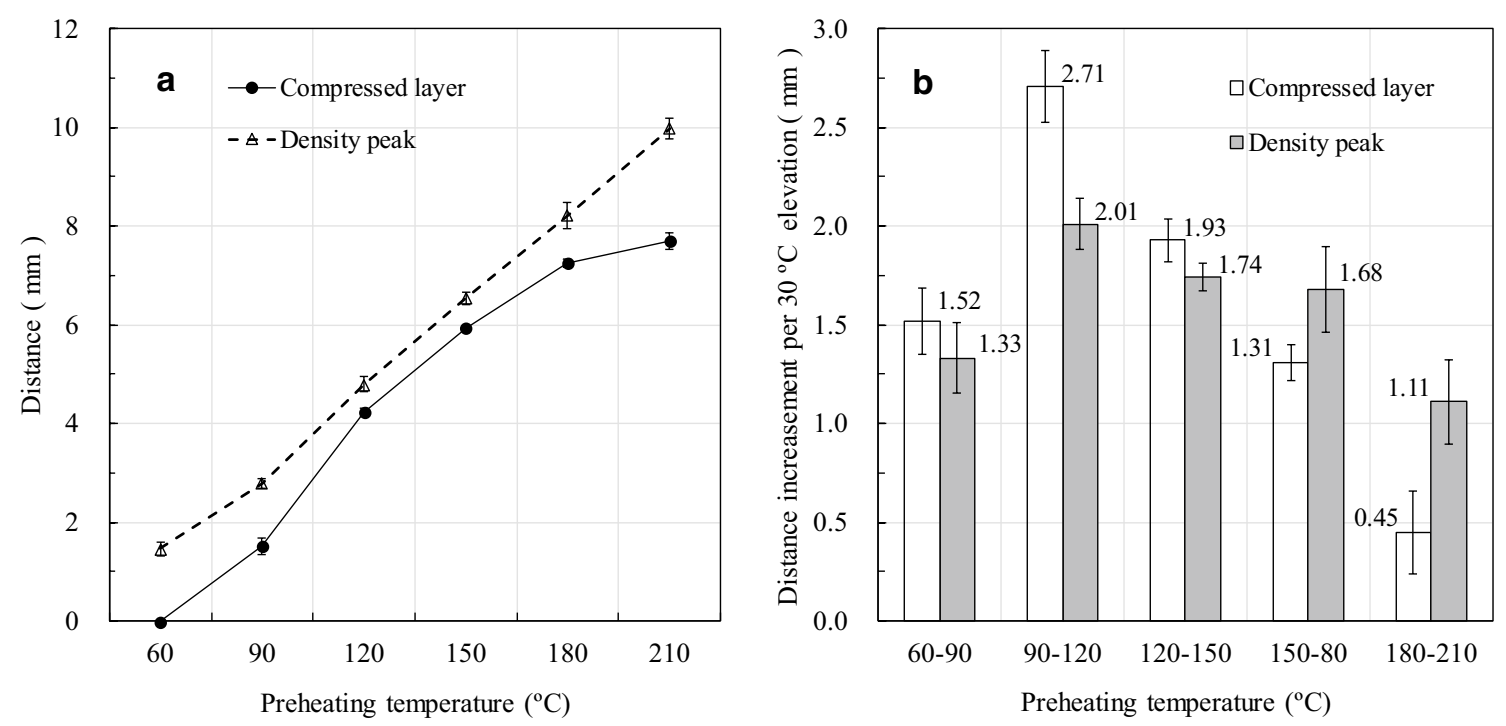

Fig. 5 Effects of preheating temperatures on the position and maximal density of compressed layers. Distance means from the position of compressed layer and density peak to top or bottom surfaces

with the elevated preheating temperature. When the preheating temperature is $60^{\circ} \mathrm{C}$, compressed layers locate on the surfaces of the compressed wood, while for compressed wood preheated at $210^{\circ} \mathrm{C}$, the distance between the compressed layer and the compressed wood surface is $7.70 \mathrm{~mm}$. At $60-210{ }^{\circ} \mathrm{C}$, temperature elevation of $30{ }^{\circ} \mathrm{C}$ results in distance (between the compressed layer(s) and compressed wood surface) increase of $0.45-2.71 \mathrm{~mm}$. At the temperatures below $120{ }^{\circ} \mathrm{C}$, the distance change as a result of $30^{\circ} \mathrm{C}$ elevation at higher temperatures is bigger than that as a result of $30^{\circ} \mathrm{C}$ elevation at lower temperature levels. Temperature elevation from 90 to $120^{\circ} \mathrm{C}$ results in the biggest distance change of $2.71 \mathrm{~mm}$. Above $120^{\circ} \mathrm{C}$, every $30{ }^{\circ} \mathrm{C}$ elevation leads to less distance change. The distance changes could be attributed to relatively slow movement of moisture and temperature at the comparatively low temperatures, and $100{ }^{\circ} \mathrm{C}$ is a phase change point for water that consumes more energy. When the preheating temperature is above $120^{\circ} \mathrm{C}$, the resulted difference of the steam pressure accelerates the moisture migration and temperature transfer $[11,12]$. When the preheating temperature reaches to $180{ }^{\circ} \mathrm{C}$, the top and bottom density peaks integrate into one in wood center, which is the maximal density in this study, namely $9.98 \mathrm{~mm}$ below the surface along the thickness direction. For poplar lumber compressed from 25 to $20 \mathrm{~cm}$, temperature elevation to $210^{\circ} \mathrm{C}$ does not result in density peak change, while the distance between compressed layer and wood surface slightly increases.

In this study, the sandwich compressing technology is further developed, which is realized via several steps. These steps involve lumber drying, soaking in water to wet the lumber surfaces, storing in plastic bags to form comparatively big moisture gradient from the surfaces to the centre of wood (namely high moisture on wood surfaces and low MC in wood centre). The wood is then preheated and compressed. Preheating of wood in this study can be considered as the hydrothermal softening process. During the preheating process, water on wood surfaces can either vaporizes into air or moves into wood [14]. After preheating, wood surfaces are dried while inside wood, both moisture content and temperature increase, forming a new moisture gradient from the center to the surfaces, namely low moisture content on the surfaces but high moisture content in the center of wood.

$\mathrm{MC}$ and temperature are the most important parameters on which wood softening and yield stress are dependent. Among the chemical components in wood, content and softening properties of lignin are the determining factors for wood softening [5, 15]. Lignin softening properties is related to moisture content. For instance, the softening temperature of oven-dried lignin is around $150{ }^{\circ} \mathrm{C}$, but for lignin with moisture content of $20 \%$, the softening temperature is only $80{ }^{\circ} \mathrm{C}[5]$.

For woods with the same moisture content, preheating contributes to a higher temperature elevation rate on the surface than that in wood center, forming a big temperature gradient along wood thickness. And higher preheating temperature results in bigger temperature gradients [16-18]. Also, preheating temperature affects moisture diffusion coefficiency and thus changes the moisture distribution along wood thickness [8, 19]. Accordingly, for wood preheated at different temperatures, different temperature gradient and moisture content gradient are both formed on the thickness direction, leading to yield stress gradient on the direction of thickness. Since some regions are of high moisture content 
and high temperature in wood, the corresponding yield stress is much smaller and these regions can be compressed much easier [20]. Accordingly, preheating at various temperatures contributes to three types of compressed layers, namely surface compressed layer, internal compressed layer and central compressed layer. These are the reasons behind our findings that our developed technology can produce sandwich compressed wood with controllable positions, thickness, and density of compressed layer(s), via optimizing water absorbance amount on wood surface, preheating temperature and time during the whole process.

\section{Conclusion}

Poplar lumbers [400 $\mathrm{mm}(L) \times 120 \mathrm{~mm}(T) \times 25 \mathrm{~mm}(R)$ ] with surfaces wetted in water can be compressed into sandwich compressed wood after preheating at $60-210{ }^{\circ} \mathrm{C}$ for $12 \mathrm{~min}$. Depending on preheating temperature, sandwich compressed wood with three structural modes, namely, surface compressed wood, internal compressed wood and central compressed wood can be formed. Density of the compressed layer(s) in wood increased gradually as results of the elevated preheating temperatures. Distance between compressed layer(s) and the wood surface was bigger when the preheating temperature was at higher levels, and preheating temperature elevation from 90 to $120{ }^{\circ} \mathrm{C}$ contributed to a maximal distance increase of $2.71 \mathrm{~mm}$. In addition, higher preheating temperatures resulted in bigger thickness of compressed layer(s) over $60-150{ }^{\circ} \mathrm{C}$ and temperature elevation from 120 to $150{ }^{\circ} \mathrm{C}$ lead to the layers integration from two into one. Further temperature elevation over $150{ }^{\circ} \mathrm{C}$ reduced the thickness of the compressed layer in wood. Moreover, cell wall bucking rather than cell wall crack occurred in compressed layer and transition layer.

Acknowledgements The authors acknowledge the financial support from the National Natural Science Foundation of China: Formation Mechanism and Controllability of Wood Sandwich Compression by Hydro-thermal Control (Grant no. 31670557).

\section{References}

1. Kitamori A, Jung K, Mori T, Komatsu K (2010) Mechanical properties of compressed wood in accordance with the compression ratio. Mokuzai Gakkaishi 56:67-78
2. Tu DY, Su XH, Zhang TT, Fan WJ, Zhou QF (2014) Thermomechanical densification of populus tomentosa var. tomentosa with low moisture content. Bioresources 9:3846-3856

3. Zhan JF, Avramidis S (2017) Transversal mechanical properties of surface-densified and hydrothermally modified needle fir wood. Wood Sci Technol 51(4):721-738

4. Huang RF, Wang YW, Zhao YK, Lu JX (2012) Sandwich compression of wood by hygro-thermal control. Mokuzai Gakkaishi 58:84-89

5. Furuta Y, Nakajima M, Nakanii E, Ohkoshi M (2010) The effects of lignin and hemicelluloses on thermal-softening properties of water-swollen wood. Mokuzai Gakkaishi 56:132-138

6. Åkerholm M, Salmén L (2004) Softening of wood polymers induced by moisture studied by dynamic FTIR spectroscopy. J Appl Polym Sci 94:2032-2040

7. Simpson WT, Lin JY (1991) Dependence of the water vapor diffusion coefficient of aspen on moisture content. Wood Sci Technol 26:9-21

8. Hrčka R, Babiak M, Németh R (2008) High temperature effect on diffusion coefficient. Wood Res Slovak 53:37-46

9. Li YJ, Li L, Zhang BG (2007) Moisture diffusion coefficient of Cunninghamia lanceolate board with non-steady state conditions. J Zhejiang Fore Coll 24:121-124

10. Udaka E, Furuno T (2005) Relationships between pressure in a closed space and set recovery of compressive deformation of wood using a closed heating system. Mokuzai Gakkaishi 51:153-158

11. Pang S (1997) Some considerations in simulation of superheated steam drying of softwood lumber. Drying Technol 15:651-670

12. Hunter AJ (1993) On movement of water through wood-the diffusion to efficient. Wood Sci Technol 27:401-408

13. Gao ZQ, Zhang YM, Wu ZQ, Wang YW, Li R, Huang RF (2017) Effect of pressurized heat treatment on spring-back of surface compressed poplar wood. China Wood In 31:24-28

14. Haque MN (2007) Analysis of heat and mass transfer during hightemperature drying of Pinus radiata. Drying Technol 25:379-389

15. Yokoyama M, Kanayama K, Furuta Y, Norimoto M (2000) Mechanical and dielectric relaxations of wood in a low temperature range III. Application of sech law to dielectric properties due to adsorbed water. Mokuzai Gakkaishi 46:173-180

16. Beard JN, Rosen HN, Adesanya BA (1983) Temperature distribution and heat transfer during the drying of lumber. Dry Technol $1: 117-140$

17. Beard JN, Rosen HN, Adesanya BA (1985) Temperature distribution in lumber during impingement drying. Wood Sci Technol 19:277-286

18. Tang YF, Pearson RG, Hart CA, Simpson WT (1994) A numerical model for heat transfer and moisture evaporation processes in hot-press drying — an integral approach. Wood Fiber Sci 26:78-90

19. Fotsing JAM, Tchagang CW (2005) Experimental determination of the diffusion coefficients of wood in isothermal conditions. Heat Mass Transfer 41:977-980

20. Inoue M, Norimoto M, Otsuka Y, Yamada T (1990) Surface compression of coniferous wood lumber I. A new technique to compress the surface layer. Mokuzai Gakkaishi 36:969-975 